\title{
THE GENES OF THE JAPANESE MORNING GLORY
}

\author{
Yoshitaka IMAI \\ Furitsu-Kôtôgakko, Meguro, Tokyo
}

Received December 9, 1937

In I930, I (Imai I93Ob) published a list of the genes that have been determined in the Japanese morning glory, Pharbitis Nil, with brief descriptions of the characters manifested by them. The list then contained I I I genes. The number of papers dealing with the genetics of this plant have reached a total of $\mathrm{I} 4 \mathrm{I}$. In this paper, I have brought together I 55 genes with short diagnoses of them, which is an addition of 44 newly determined genes to the previous revised list. The linkage groups have been dealt with in other publications (Imai I93Ia, I93Id, I933; Imai and Tabuchi 1933; Imai and Kanna 1935).

The wild form of the Japanese morning glory, the home of which we think is Asia, is not yet known to the scientific world. According to old literature, the original form introduced into Japan from China as a medical herb over a thousand years ago, bore normal, or three-lobed, leaves and bloomed blue funnel-shaped flowers, which is regarded as the genetic standard. There are 20 dominant genes in what are otherwise recessives, being about I 3 per cent of the total.

\section{List of Genes}

acuminate, ac (ac L. G. ${ }^{1)}$ ): Stalk broadened at junction of cotyledon. Lamina deeplobed and sharp-pointed; lobes rolling backwards; sometimes compound. Corolla funnel-shaped, with narrow opening; margin turned outward, and sometimes split irregularly ; flower-tube comparatively long. Fertility low. Jap. name "Nanten," or nandina.

albescent, $a b$ : Cotyledon with white or whitish smear; stalk of cotyledon pale or white. Bud appearing between cotyledons distictly white. First one or two leaves of seedling whitish, but not permanently so ; leaves of grown-up plant apparently green, or normal. Viability of seedling low. Fertility normal (Imai I929).

albescent-enhanced, ab-e: Strengthens albescent diagnosis of seedling. Central part of cotyledon sometimes whitish, becoming somewhat deformed. Appeared by mutation under Imai's observation (Miyake and Imai 1934).

albino, al: Cotyledon immediately after germination almost white, with a little

今北喜孝： 朝顏の遺傳子

I ) " L. G." is an abbreviation of " linkage group." 
chlorophyll ; turns pure white later; seedling dies a few weeks after germination without forming leaves. Yasui (1920, I934) made a study of this. In Imai's culture it occurred twice by mutation (1927b, r93ob; Miyake and Imai 1934).

amber, am: Vivid yellow cotyledon; non-viable. Appeared by mutation (Miyake and Imai 1934). A smilar seedling was described by Yasui (1934).

anchor, ar: Petiole broadened at junction of lamina, but not crooked. Jap. name "Ikari."

Blizzard-I, BzI (ac L. G.): Manifests Blizzard character under cooperation of Blizzard-2. Deep-coloured stripes or areas occur in light-coloured background, or vice versa ; frequently whitish spots appear sparsely over the deep-coloured background. Variegation varies considerably, resulting sometimes in the extreme case of nearly self-coloured flowers of light or heavy shade.

Blizzard-2, Bzz (dk L. G.): Complementary to Blizzard-I in production of Blizzard character.

Blozon-I, BI (v L. G.): Stalk broadened at junction of cotyledon, and also base of lamina, making it crooked. Jap. name "Rimpu."

Blown-2, B2 (p I. G.) : Less conspicuous than Blown-I.

blowen-3, b3: Still less conspicuous than the preceding; hardly noticeable in upper leaves.

bobbed-I, bbI (co. L. G.): Hairs bobbed (Imai I933).

bobbed-2, bliz (py L. G.): Short hairs (Imai r933).

broad, $b d$ : Median lobe of leaf broad, like normal heterozygous for cordate; somewhat deformed.

broken, bk: Leaf somewhat deeply lobed ; corolla irregularly split. Mutant obtained by Imai.

brozen, br (v. L. G.): Seed colour brown. Hagiwara (1937a) found a mutable line.

buff, bf: Seed colour lighter than brown.

bush, bu: Bush habit; branches grow up together with main stem; only about 2 feet

high. Fertility low. Appeared by mutation in Imai's culture (1927b); lost.

bushy, bs (y L. G.): Leaf small; bush growth (Imai 1933).

chestnut, cn (p L. G.) : Light brown seed-coat ; lighter than brown (Imai 1933).

chocolate, ch: Seed colour darker than cocoa. The order of intensity of seed colourblack (normal), chocolate, cocoa, brown, chestnut, buff, ivory, white.

cocoa, ca: Seed colour a little darker than brown. Appeared by mutation (Imai I93 Iе).

contorted, $c d$ : Rays of corolla containing chlorophyll, prevents flower from opening completely, making it crooked and contorted; sometimes hard to open without aid. Jap. name "Nejiume."

contracted, ct (ct L. G.) : Cotyledon and leaf contracted and dark green ; texture thick and brittle. Flower small; so also seed. Sometimes mutable, reverting to normal (Imai I934b). Jap. name "Uzu."

corlate, co (co L. G.): Heart-shaped leaf. Jap. name "Maru-ba."

couple, $c u$ (v. L. G.): Two flower-buds grow side by side in a leaf-axil ; one blooming a few days later than the other.

cream, or (ct L. G.): Creamish flower with a few anthocyanin flakes. HypocotyI 
green, sometimes striped. Mutable, frequently reverting to normal (Imai I927b). creased, $f e^{c}$ (co L. G.): Recessive allel of feathered. Cotyledon slightly crumpled; leaf nearly flat or slightly crumpled. Flower feathered; apparently no alternation of sexual organs ; fertility low (Imai r93 Ic). Jap. name "Ranjishi."

crêpe, cp (co L. G.) : Crêpe texture of leaf; cup flower variable; hair on flower-bud. Jap. name "Chirimen."

crisscrossed, cs (dk L. G.) : Flower split down to base of tube ; narrow petals crossing one another at neck of tube. Sometimes imperfectly split, with whitish lines or grooves left on tube, where splits. Calyx somewhat broad. Reappeared by mutation in Imai's culture (I927b). Jap. name "Ishidatami."

crumplea- $x, i I$ (v L. G.): Lamina uneven, or crumpled; diagnosis uncertain at times in later growth. Behaves as dominant on delicate, creased, crêpe, and deformed genotypes. Jap. name "Uchikomi."

crumpled-2, c2 (dl L. G.): Character similar to that of crumpled-I.

curly, cy: Cotyledon small. Lamina attaches to petiole in subrectangular position, presenting an eddy arrangement of leaves. Completely sterile. Mutant obtained by Terao and U (1930).

deep-crumpled, dc: Leaf deeply crumpled. Occurred by mutation in Tabuchi's culture (1935a).

defectice, $a v$ : Seed very thin and rusty tan in colour; air-dried seed weighing about one-half that of normal. Seedling with small and deformed cotyledons ; less vigorous. Fertility somewhat low. Appeared by mutation under Imai's observation (1929).

deficient, df: Sometimes fine variegation in cotyledon, with irregular missing of parts. Same character in leaf; flower sometimes split and deformed with whitish stripes (Imai 1925b). Variegation and deficiency due to recurrent exomutation of plastid (Imai 1936, 1937).

deformed, de (y L. G.): Cotyledon with shallow lobing and long stalk. Petiole long; lamina with thin mesophyll; sometimes deformed. Plant growth peculiar. Flower doubled, bearing scarcely any sexual organs. Propagated through "parental stocks" heterozygous for deformed. Jap. name "Tenaga-botan."

delicate, al (dl L. G.): Stable delicate, recessive allel of unstable delicate (Tabuchi 1935a).

delicate-mutable, dlm (dl L. G.): Cotyledon with narrow lobes. Leaf with sharppointed lobes and less-protruding shoulder; mesophyll thin. Cotyledon and lamina slightly crumpled. Flower split into five narrow petals; fertility low. Mutable, reverting to normal. A highly mutable line was obtained by Tabuchi (1935a), probably due to new mutation.

Dilute, $D$ (dp L. G.): Standard flower colour, Ridgway's "Bradley's blue," diluted to "Amparo blue."

dotted, dt: Stem and flower dotted, mutable to normal. Mutant obtained by Terao and $\mathrm{U}$ ( $\mathrm{I} 930)$.

dragonfly, $d g$ (dp L. G.) : Lamina with elongated median lobe and one or two narrow side-lobes on either side. Flower somewhat large; rays of corolla rarely exceeding five. Jap. name "Tombo-ba."

dragonfly-suppressed, $d g-s$ (r L. G.): Suppressor of dragonfly, resulting in normal, 
three-lobed leaf.

duplicatcd, ap (dp L. G.): Flower doubled, including flower-buds with sepals, without sexual organs. Propagated from "parental stocks" heterozygous for duplicated. Reappeared by mutation in Imai's culture ; lost. Jap. name "Botan."

duskish, dk (dk L. G.): Colour of flower more dilute than dusky, having an unique hue, or, when intense, Ridgway's "Vinaceous purple." Duskish-r composed of at least four allels, highly-ruled, ordinary-ruled, unstable-plain, and near-stable-plain. Becurrent mutations occur in various ways (Imai 1935).

duskish-2, dk2 (?) (ct. L. G.): Hagiwara's duskish (1930, 1937b) links with sidereduced, which, in turn, links with contracted; hence assumed to be duskish-2.

duskv, dy (y I. G.) : Colour of flower, when intensified, Ridway's " Dark hyssop violet." dzarf, dw' (dl I. G.) : Hypocotyl short, with cotyledons of hard texture. Stem thick; about 2.5 feet high, with short internodes. Star-shaped corolla with short peduncle. Reappeared under Tabuchi's culture (I935a). Jap. name "Kidachi."

dzuarfish, dh; Dwarf, about $\mathrm{x}$ foot high. Cotyledon small ; sterile. Mutant obtained by Terao and $\mathrm{U}$ (1930).

dwarfy, da: Stem short; internodes short, with overlapping leaves; flower normal. Appeared by mutation (Imai i $927 \mathrm{~b}$ ); lost.

Expanded. Ex (ct L. G.): White margin extended broadly in corolla, leaving starlike coloured parts.

extended, $e$ (dp L. G.): Working on faint, results in full-coloured flower-tube.

faded, $f d$ (v L. G.) : Hypocotyl green, except lower part, which is faintly coloured by anthocyanin pigment. Flower faintly coloured; faded flower with a coloured ring just inside the white margin, when it carries Margined genotype.

faint, ft: In magenta or red flower resulted in faintly coloured tube, especially at bottom of tube.

fasciated-I, $f_{I}$ (p L. G.): Fasciated stem caused by three recessive genes, fasciated- $\mathrm{I}$, fasciated-2, and fasciated-3. Frequently fails to be fasciated, remaining as normal, due to fluctuating manifestations. Flower sometimes deformed; fertility low.

fasciated-2, f2 (p L. G.): Works in conjunction with fasciated-r and fasciated-2.

fasciated-3, $f_{3}$ (v L. G.): One of three polymerous genes for fasciated character.

feathercd, $f_{e}$ (co L. G.): Cotyledon and leaf greatly crumpled or rolled; corolla feathered, with supplementary petaloid pieces, sometimes split irregularly. Fertility usually either low or perfectly sterile. Jap. name "Shishi."

featheroid,fr: Leaf small; growth less vigorous; flower small and feathered. Appeared by mutation in a recessive ratio in Imai's hybrid progeny, $1933:$ lost.

flecked-I, wa af (dp L. G.) : Allelic to white-2a. Flecked corolla with coloured tube. Flecking evident in autumn.

flecked-2, w2bf (ct L. G.): Green hypocotyl, sometimes striped; flower with fine anthocyanin flakes. Mutable, producing normal flowers; particularly suited to the study of mechanism of bud variation (Imai 193 rb, 1934b; Kihara 1934).

folded, fol: flower-bud not open, remaining folded all through its existence. Anthers do not shed pollen; sterile. Appeared by mutation (Imai r93 re); lost.

foliate, fo (r L. G.) : Modifier of terminal. Peduncle very elongated, bearing crowded small, roundish leaves; frequently with branchlets. 
giant, gi : Cytyledon and leaf stout and deep green. Flower large ; fertility very low. Appeared by mutation under Hagiwara's observation (1926); lost (observer's private communication).

glabrous, $g$ : Hairs scanty; smooth to touch.

slabrous-suppressed, $g$-s: Suppressor of glabrous, giving hairy foliage.

Globose, Gb (co L. G.): Leaf roundish ; lobes not very conspicuous. Flower larger, frequently with more than five rays (Imai and Kanna I934).

half-zuhite, hw: Lower half of flower-tube white.

Hederacea-leaf, Co ${ }^{h}$ (co L. G.) : Introduced by species hybrid, P. hederacea $\times P$. Nil (Hagiwara 1937c). Median lobe of lamina deeply incised and side-lobes frequently again lobed.

intense-I, iI (ct L. G.) : Intensifier of flower colour, giving Ridgway's " Dark bluish violet."

intense-2, i2 (p L. G.): Intensifying flower colour (Imai I933)

interaxil-green, ig (ct L. G.): Green hypocotyl; green stem with anthocyanin colour on base of branches and peduncles.

ivory, $3 w^{i}$ : Allelic to white-3. Seed colour ivory. Stem green; flower white, with white tube.

liglit-I, ltI (y L. G.): Colour of hypocotyl dilute; flower also light.

light-2, lt 2 (p L. G.) : Character similar to that of light-I.

light-3, lt3: Mutant obtained by Katayama (1936). Affecting flower colour, "Amaranth purple" reduced to "Pale amaranth pink."

lilliput (formerly pigmy), lp (ct L. G.): Hypocotyl very short. Cotyledon thick, crumpled, and deep green, with very short stalk. Between cotyledons there appear a few thick and crumpled leaves with very short petioles. Seedling stops growth after this stage. Appeared by mutation under Imai's observation (r93 Iе); lost.

Lined, $L n$ : Irregular stripes on dilute background of corolla; variegation varies considerably.

lobeless, ls: Leaf roundish; completely sterile. Mutable, reverting to normal. Appeared by mutation in Terao and U's culture (I930).

magenta, mg (ac L. G.): Flower colour purplish red, or Ridgway's "Rood's violet" when intensified. Hypocotyl dark red instead of dark purplish-red. Hair white instead of brownish. At times mutable (Kihara 1934).

male-sterile-I, msI (v L. G.): Anther abortive, but ovule normal (Imai 1933).

male-sterile-2, ms2: Leaf somewhat small, flower also small with almost abortive anthers. Appeared by mutation under Imai's culture (I935); linked with piebald (Imai and Kanna 1935b).

male-sterile-3, ms3: Flower small ; anther thin, shrivelled, and coloured brownish. Mutant obtained by Imai and Kanna (r635b).

maple, $m$ (y L. G.): Lobes of cotyledon arranged in parallel; veins evident. Leaf lobed deeply like that of maple tree; normal maple five-lobed. Flower split regularly ; pistil sometimes deformed ; fertility low. Jap. name "Tatsuta."

Margined- $I$, MrI (ct L. G.): In conjunction with Margined-2 manifests white margin in corolla. Jap. name "Fukurin." 
Margined-2, Mrz (ac L. G.): Complementary to Margined-r for the manifestation of white margin.

Margined-3, Mr3 (p L. G.): Complementary to Margined-I and Margined-2 in producing white margin (Imai I933).

Margined-fluctuated, Mr-f (sp L. G.): Modifier of Margined. Fluctuating the manifestation of white margin.

Margined-reduced, Mr-r (ct L. G.): Modifier of Margined, reducing amount of white margin.

margined-slight, $m r-r^{s}$ (ct L. G.): Allelic to Margined-reduced. Producing very small amount of white margin in corolla.

Margined-suppressed, Mr-s: Suppressor of Margined; inhibiting completely white margin, resulting in normal, self-coloured flower.

miniature, mi : Cotyledon and leaf very small; flower also very small and split, blooming in small clusters ; sterile. Reappeared by mutation under Imai's observation (1927b) ; lost. Jap. name "Tsubame," or swallow.

miniature-mutable, mi" $i^{m}$ : Unstable miniature, obtained by Terao and U (1930).

nipped, np: Weakly nipped at tips of rays of corolla. Appeared by mutation under Imai's observation in a retracted line in 1934 ; lost.

no-lobe, $n l$ : Working on Globose, results in nearly lobeless leaf. Lamina of no-lobe

Globose oblong, sometimes with inconspicuous lobes (Imai and Kanna I934).

no-lobe-suppressed, nl-s: Working on no-lobe Globose compound, produces normal

Globose by suppressing gene no-lobe (Imai and. Kanna 1934).

palmate, $p l$ (co L. G.): Leaf five-lobed. Flower funnel-shaped.

pear, $p$ ( $\mathrm{p} \mathrm{L.} \mathrm{G.):} \mathrm{Oblong} \mathrm{leaf} \mathrm{without} \mathrm{side-lobes;} \mathrm{side-lobes} \mathrm{sometimes} \mathrm{develop.} \mathrm{Co-}$ tyledon with Blown-like character to a very slight degree. Flower somewhat small. Jap. name "Kujaku."

pear-petaloid, $p^{\phi}$ (p L. G.) : Allelic to pear. Pear leaf; stamen petaloid from filament to anther ; petalody variable.

petaloid, pt: Stamen petaloid from anther to filament; marked variation occurs.

piebald, $p b$ : Black seed sometimes piebald with dirty yellow; yellowish patches occur at back of seed, and then extend to abdomen, eventually becoming entirely yellowish when the remaining minute black part around micropyle diminishes. Linked with male-sterile-2. Mutant obtained by Imai and Kanna (1935b).

pigmy, $p g$ : Cotyledon small ; small leaves crowded on very short stem ; sterile. Mutant obtained by Terao and U (1930).

pine, $m^{p}$ (y L. G.) : Recessive allel of pine-mutable (U, unpublished data). Constant form of pine.

pine-mutable, $m^{m m}$ (y I. G.): Allelic to maple (U, unpublished data). Cotyledon very small; leaf filiform; flower split very narrow. Highly mutable, reverting to normal. Reappeared twice by mutation independently in Imai's (r927b) and U's (1930) cultures. Jap. name "Matsu-ba."

$p i p y, \not p$ : Flower small and pipy. Mutable, changing to normal. Appeared as mutant in Imai and Kanna's culture (1935a).

pollen-sterile, ps (y L. G.): Pollen sterile; linked with dusky. Determined by Yasui (r934). 
polymorphic, $p y$ (p L. G.): Cotyledon with retracted, roundish lobes, sometimes split, or compound. Leaf split irregularly, with sharp-pointed lobes, but sometimes does not. Corolla creased, with super-numerous rays ; often irregularly split. Fertility low. Jap. name "Rangiku."

precocious, pc (co L. G.): Early blooming; flower-buds appear on lower nodes of stem. Projected, $P j$ : Leaf with small projections on its margin.

projected-enhanced, pj-e: Modifier of Projected. Leaf with large projections.

purple, pr (dk L. G.): When intensified, flower colour Ridgway's "Cotigna purple." Sometimes mutable (Imai i934b).

Rayed, Ry (ct L. G.): Flower with coloured rays, colour fading off in regions between rays. Reappeared by mutation in Imai's culture (I93ob).

Restricted, Rt (co L. G.): Restricted distribution of hairs on calyx (Imai I933).

retracted, $r(\mathrm{r}$ L. G.): Cotyledon with roundish lobes. Leaf with retracted lobes; median lobe, especially, greatly shortened. Corolla large, frequently with over five rays. Sometimes numerous sepals and bracts. Fertility low. Jap. name "Suhama." reversed, cppr (co L. G.): Recessive allel of crêpe. Flower reversed to cup; leaf not crêpe.

rootletless, $r l$ : Cotyledon usually with shallow lobing. Rootless in early seedling stage; later thick and crooked rootlets appear. Appeared by mutation in Imai's culture (193 Ie). Deficiency of rootletless segregates in hybrid progeny due to slow pollen-tube growth (Imai r634a); lost.

semi-contracted, sc (co L. G.): Cotyledon and leaf somewhat thick and brittle. All organs somewhat contracted.

sepalobate, $s l$ : Modifier of maple, resulting in seven-lobed leaf.

shallow, sw: Cotyledon roundish, with shallow lobing; sterile. Mutant obtained by Terao and U (1930).

shrubbish (formerly shrubby), sb (ct L. G.): Seedling somewhat small. Lobes of leaf sharp-pointed; of hard texture. Branches occur on lower part of main stem. Obtained by mutation in Imai's culture (r93 Ie); lost.

shrubby, sh: Dwarf, less than I.5 feet high. Branches crowded, forming bush growth; sterile. Mutant obtained by Terao and U (1930).

side-reduced, $s r$ (ct L. G. ?): Side-lobes of leaf retracted and roundish. Jap. name "I Iana-ba."

smeary, $f d^{s}$ (v L. G.) : Dominant allel of faded. Colour of flower dilute, or, when intensified, Ridgway's "Light violet-blue." Heavily coloured ring occurs in inner region adjoining white margin when it carries Margined genotype.

speckled, sp (sp L. G.): Hypocotyl and stem speckled with anthocyanin pigment. Fine spots distributed over corolla; speckling varies considerably. speckled composed of some mutable allels (Tabuchi, unpublished data).

speckled-reduced, sp-r (y L. G.): Modifier of speckled. Green hypocotyl ; nearly green stem, coloured very dilutely by anthocyanin on base of branches and peduncles. Flower with or without a few fine spots on otherwise pale-blue, yellowish or white background.

spheloid, sph: Seed small, roundish and brownish.

star, $s$ : Similar to contracted, except that flower is star-shaped. Jap. name "Kikyo- 
Uzu."

Stellate, Sl: Modifier of Margined, working on homozygous Margined flower. White margin broadly extended, leaving coloured star-shape part in corolla. Studied by Hagiwara (1922).

sterile, str: Leaf and flower small ; plant growth poor. Pistil and stamen abortive; anther small and shrivelled. Appeared by mutation (Imai and Kanna I935b).

Striated, $S a$ (sp L. G.): Dilute colour of flower brushed by very fine stripes ; colour somewhat faded off to margin of corolla; flower-tube white; when heterozygous, flaking conspicuous (Imai r933).

striped-I, st (dp L. G.): Stripes occur irregularly on dilute background of corolla. striped-2, st2 (p L. G.): Stripes appear irregularly in corolla (Imai 1933).

stunted, sd: Growth slow and stunted. Stem stout; leaf crumpled; flower irregularly split; fertility very low. Appeared by mutation in Imai's culture (1927b) ; lost.

syncotyl, sn: Two cotyledons jointed; sterile. Mutant obtained by Terao and U (I930).

terminal, $t$ : Peduncle with a few axillary flower-buds, bearing small leaves without side-lobes ; terminal flower with no bracts; axillary flowers with two or three small bracteal leaves on stalks; axillary peduncles sometimes bear subaxillary flowers. Terminal flower blooms first. Mutant obtained by Imai (1927b).

tinged, tg: Colour of flower considerably diluted.

trilobate, $t l$ : Modifier of maple, reducing number of lobes into three.

tube-zohite-I, twI (ct I. G.): Flower-tube white.

tube-white-2, tw2 (sp L. G.): Flower-tube white (Imai I933).

variegated, $v(\mathrm{v} \mathrm{L.} \mathrm{G.):} \mathrm{White} \mathrm{or} \mathrm{whitish} \mathrm{variegation} \mathrm{in} \mathrm{leaf} \mathrm{;} \mathrm{stem} \mathrm{with} \mathrm{white} \mathrm{stripes.}$ Cotyledon frequently variegated. Seed brownish, with black stripe on back. Variegation due to recurrent exomutation and automutation of plastid (Imai 1936, 1937).

variegated-reduced, $v$-r: Leaf finely variegated with very dilute green colour ; variegation somewhat netlike, due to recurrent plastid mutation.

velvet, $v t$ : Long hairs on seed-coat.

virescent, vi: Cotyledon and leaf pale green. Viability low; growth slow. Leaf and flower small, due to malnutrition. Mutated under Imai's observation (Miyake and Imai I934).

white-I, wI (sp L. G.): White flower with coloured stem ; flower-tube always white.

white-2a, w2a (dp L. G.): White flower with green stem; flower-tube generally coloured ; corolla sometimes faintly coloured, due to environment. Dominant allel works complementarily to dominant allels of white- $\mathrm{I}$, white-2b, and white- 3 in production of coloured flower.

white-2b, was (ct L. G.): White flower with green stem ; flower-tube white.

white-3, w3: White flower with green stem; flower-tube white; seed white.

willow, $m^{\text {w }}$ (y L. G.): Recessive allel of maple. Cotyledon with narrow lobes; veins clear. Leaf narrow like that of willow tree. Flower split into five narrow petals; sometimes crooked. Usually sterile, but anther frequently contains good pollen. Mutable, altering to maple (Imai r925a); rarely reverts to normal (Tabuchi I935b). 
zurinkled, wr: Corolla wrinkled, somewhat star-shaped; fertility somewhat low. Mutable, reverting to normal (Imai r927b ; Katayama 1936). Reappeared by mutation in Imai's culture. Jap. name " Chijimi-zaki."

wrinkloid, wl: Corolla wrinkled, but inconspicuously. Mutant obtained by Imai and studied by Katayama (1936).

xanthic (formerly golden), $x$ : Vividly yellow; green spots frequently occurring in cotyledon; dies without unfolding leaves. Sometimes one or two leaves develop when green areas of cotyledons are large. Green spots or areas due to recurrent mutations. Appeared by mutation in Hachiuma's garden (Imai 193ob ; Miyake and Imai 1934). Mutant obtained by Terao and U (1930) probably the same as this. yellow, $y$ (y L. G.): Foliage yellowish green.

yelloze-mutable-I, ym1 (y L. G.): Dominant allel of yellow. Green spots and patches occur in yellow leaf, due to somatic mutation. Mutable, reverting to normal (Imai r927a, I930a). Jap. name "Matsushima."

yellow-mutable-2, ym2 (y L. G.): Allelic to yellow and yellow-mutable-I ; mutability higher than yellow-mutable- I (Miyazawa 1929, I932 ; Imai r934b). Mutant obtained by Miyazawa.

yellowy, ye: Cotyledon yellowish green, often with green patches. Young leaf yellowish green and finely mottled with green spots; later, green mottling extends over leaf to such a degree that difficult to distinguish it from normal leaf. Frequently green spots or areas due to somatic mutation occur; mutable. Appeared by mutation in Imai's culture (r934b).

\section{Literature Cited}

Hagiwara, T. I922. Genetic studies of corolla-design in the morning glory. Bot. Mag., Tokyo 36 : 205-225. In Japanese.

— 1926. Genetic studies of leaf-character in morning glories. V. Bot. Mag., Tokyo 40 : 226235. In Japanese.

-1930. Genetic studies of flower colour in the morning glory. IV. Bot. Mag., Tokyo 44 : 573580. In Japanese.

- 1937a. On a mutable gene of the seed coat colour in Plarbitis Nil. Jap. Jour. Genet. 13 : I85-192. In Japanese.

— I937b. New genes for the flower size of Pharbitis Nil. Botany a. Zoology 5 : 1429-I432. In Japanese.

- 1937c. On multiple allelomorphs concerning leaf shapes observed in Pharbitis hederacea $\times P$. Nil. Botany a. Zoology 5 : 2160-2162. In Japanese.

IMAI, Y. I925a. Genetic behaviour of the willow leaf in the Japanese morning glory. Jour. Genet. 16 : 77-99.

- 1925b. Inheritance of deformed leaves in Pharbitis Nil. Bot. Gazet. 80 : 276-287.

- 1927a. A genetic study of green-variegated yellow leaves in the Japanese morning glory. Jour. Genet. $17: 329-348$.

- 1927b. The vegetative and seminal variations observed in the Japanese morning glory, with special reference to its evolution under cultivation. Jour. Coll. Agri., Tokyo Imp. Univ. 9 : 223-274.

-.._- I929. The segregation of albescent seedlings and the mutation to defective seeds in a pedigree 
of the Japanese morning glory. Amer. Nat. 63 : I5 I-I59.

ImA!, Y. I93oa. Studies on yellow-inconstant, a mutating character of Pharbitis Nil. Jour. Genet.

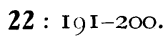

- I930l. I)scription of the genes found in Pharbitis Nil. Genetica 12 : 297-318.

— 1931a. Linkage studies in Pharbitis Nil. I. Genetics $16: 26-41$.

- I93 Ib. Analysis of flower colour in Pharbitis Nil. Jour. Genet. $24: 203^{-224}$.

- 1931c. Creased flowers of Pharbitis Nil. Zeitschr. f. ind. Abst.- u. Vererbgsl. 58 : $248-258$.

— I93Id. I inkage studies in Pharbitis Nil. II. Zeitscher. f. ind. Abst.- u. Vererbgsl. 58: 317$33 \mathrm{I}$.

- 1931 Ie. New mutant characters of the Japanese morning glory. Jour. Hered. $22: 36 \mathbf{I}-366$.

— 1933. Linkage studies in Pharbitis Nil. III. Zeitschr. f. ind. Abst.- u. Vererbgsl. 66 : 219235 .

1934a. The deficit of rootletless segregates in Pharbitis Nil. Jap. Jour. Genet. 9: I39-I42.

- I934l. On the mutable genes of Pharbitis, with special reference to their bearing on the mechanism of bud-variation. Jour. Coll. Agri., Tokyo Imp. Univ. 12 : 479-523.

1935. Recurrent reversible mutations in the duskish allelomorphs of Pharbitis Nil. Zeitschr. f. ind. Alsst.- u. Vererbgsl. $68: 242-264$.

- 1936. Chlorophyll variegations due to mutable genes and plastids. Zeitschr. f. ind. Abst.u. Vererbgsl. $71: 6 \mathbf{I}-83$.

- 1937. The behaviour of the plastid as a hereditary unit: The theory of the plastogene. Cytologia, Fujii Jubilee Vol. 934-947.

- In press. Genetic literature of the Japanese morning glory. Jap. Jour. Genet.

Imat, Y. and Kanva, B. I934. Linkage studies in Pharbitis Nil. IV. Genetica 16:467-475.

—_ - I935a. The pipy flower of Pharbitis Nil as a mutable character. Jour. Genet. 30 : 107-1 14 .

- $-1935 \mathrm{~b}$. Sterile and male-sterile flowers and the linked piebald seed of the Japanese morning glory. Jap. Jour. Genet $11: 215-218$.

ImAI, Y. and TABuchi, K. I933. A provisional map of the yellow chromosome of Pharbitis Nil. Zeitschr. f. ind. Abst.- u. Vererbgsl. $66: 236-244$.

Katayama, Y. I936. Unstable wrinkled and stable wrinkloid flowers of the Japanese morning glory. Jour. Coll. Agri., Tokyo Imp. Univ. $13: 443-45^{2}$.

Kinara, H. I934. Vererbungsstudien über eine 'flecked'-Sippe bei Pharbitis Nil. I. Botany a. Zoology 2 : I80I-I8I4. In Japanese.

Mrakf, K. and ImaI, Y. 1934. Chlorophyll deficincies in the Japanese morning glory. Jour. Coll. Agri., Tokyo Imp. Univ. 13 : 27-44.

Mryazawa, B. I929. On the inheritance of the "Matsusima "-variegation in the Japanese Convoliulus. Jap. Jour. Genet. $4: 167-184$. In Japanese.

1932. On the Matusima-variegation in Japanese morning glory. Bull. Miyazaki Coll. Agri. a. Forestry $4:$ I I I-I25. In Japanese.

TABuch!, K. I935a. The mutable behaviour of delicate genes in the Japanese morning glory. Jour. Coll. Agri., Tokyo Imp. Univ. $13: 373-395$.

- 1935b. A study on the mutability of the willow leaf in the Japanese morning glory. Jour. Coll. Agri., Tokyo Imp. Univ. $13: 415-430$.

Tfrao, H. and U, N. I93o. Studies on the appearance of mutation in the morning glory. Jap. Jour. Genet. 6 : 195-198. In Japanese.

$\mathrm{U}, \mathrm{N}$. 1930. On the recurring mutation of pine type of morning glory. Jap. Jour. Genet. 6 : 199-202. In Japanese.

YAsu, K. I920. Genetical studies in Japanese morning glory. I. Bot. Mag., Tokyo 34 : I4I-I45. In Japanese.

- 1934. On the lethal genes in Pharbitis Nil. Jap. Jour. Genet. 9 : I $14^{-1}$-186. In Japanese. 